\title{
MULTI-DIMENTIONAL CLASSIFICATION OF TYPES AND FORMS OF CORPORATE EDUCATION
}

\author{
Alfiya Rafisovna Masalimova and Lidiya Leonidovna Sabirova
}

Kazan (Volga region) Federal University, Kremlyovskaya Street, 18, Kazan 420008, Russia

Received 2014-04-10; Revised 2014-04-11; Accepted 2014-04-19

\begin{abstract}
The task of this article is: To reveal the essence and content of the notion "corporate education"; to identify features of modern corporate education models; to develop classification of corporate education types and forms and to give their theoretical distifying. The research is based on a comparative approach, which allows to identify the features of the models, types and forms of corporate education suitable for their use according to socio-economic conditions and the enterprises needs in their employees training. The study reveals the main point of such corporate education models as problem-oriented, complementary, displacing, innovative, personality-oriented, informational-consultative, metacognitive, multiplication, leader, corporate education and corporate competition models, which exist in corporate training practice. The main focus is made on the theoretical justification of types and forms of specialists' corporate education in modern enterprises and on the development of their classification at the local, scale, time purpose peculiarities of which are disclosed in the presented types and forms of corporate training. Their kinds and forms selection in corporate training process is resulted from socio-economic and organizational-pedagogical conditions of enterprises to implement their staff training. The classification of types and forms of corporate training can be useful for teaching and methodical centers of the enterprises in their personnel in-house training organization and planning, for training centers and workers, specialists and enterprises and organizations managers training, as well as for researchers, who is involved in structural and systemic analysis of corporate education problems. On the effectiveness of companies corporate training does not affect chaotic using of the presented forms and types as of in-company, so of out-of company training, but their system integrity and consequent combination.
\end{abstract}

Keywords: Modern Industry, Corporate Ideology, Multi-Dimensional Classification, Types and Forms of Corporate Education, In-House Training Models

\section{INTRODUCTION}

Corporate education in the broad sense is aimed at satisfaction of social educational needs in the sphere of common (material) production. In the narrower sense, corporate education is the forming mechanism of large and first-rate companies to accomplish professional education under functional crisis and mismatch between corporate needs and our educational system outcomes.

Modern production has its own requirements in comparison with the previous one, because it doesn't requires personalities which possess only the range of professional competencies needed to solve some separate problems, but opponents who can support and guide the strategy of the company in the whole, in this regard, the most important factor of the enterprises efficiency is human potential which is capable to generate such behavior, which would allow businesses not only surviving in an unstructured situation, but also contribute to their sustainable development, which can only be achieved in close union of science, education and industry that can support a constructive dialogue based Corresponding Author: Alfiya Rafisovna Masalimova, Kazan (Volga region) Federal University, Kremlyovskaya Street, 18, Kazan 420008, Russia 
on advanced deep reflection of the changes taking place (Nelson and Phelps, 1966; Seddigi et al., 2009).

Corporate education is considered to be a vivid trend of the modern educational practices bringing it together with current production needs. As the main reason behind this trend lies an obvious fact that currently the traditional system of professional education financed by the State does not catch up with the real needs of production sector and labor market. Taken as the alternative corporate education in this case meets the employers' requirements at the most and can easily be located where their own workforce and professional activities are (Klucharev, 2010).

Corporate education becomes more and more popular at present; it helps to form a favorable industry image, develops common corporate goals and values, heightens strategic communications and enriches corporate culture level (Masalimova, 2013). Corporativity is a broader concept: As for corporate professional education, corporativity is related to the principle determining the integrity of quality improvement process, steadiness, advanced nature, diversification and scientific environment of their training.

\section{MATERIALS AND METHODS}

The "corporation" concept derives from the Latin word "corporatio", which means to unite, the union or community (Ozhegov and Shvedova, 2007).

Russian Managers Association understands under the corporate education the in-house education system consolidated under the common development concept and designed for all levels of managers and specialists.

Corporate education can be described as the accumulation and transmission systems of various knowledge types: Economic, technological, industrial, organizational, knowledge in the sphere of corporate culture, professional ethics, management and others in order to achieve effectively the Company's goals (Minzov, 2014).

Corporate ideology is rationally detached system of ideas (Manheim, 1994), determining the development of the corporation as well as the consciousness and behavior of its members. Ideology includes strategic ideas regarding its sociocultural mission, corporate philosophy of the organization as a whole. This can be the ideals-targets, a basic understanding of the team, its formal and informal structure. Corporate ideology necessarily should reflect the specific nature of the organization and include the unique ideas and knowhow. The same ideology can be effective in one organization and adverse in another one (Tyunnikov and Maznichenko, 2004).
At present under corporate education one should understand a process of professional training, as well as further improvement of specialists' competencies through multidimensional interaction between education, science and production of a single industry focus.

In order to understand the problems arising in corporate education system, it seems necessary to assess the existing models in practices of corporate education, which correspond with specific requirements of the organization of educational process in enterprises.

Problem-oriented model of corporate training based on psychological and methodical approach allows taking into account a wide range of tasks of personnel corporate training, using the "problem situation" method, which perfectly fits into the everyday life of the enterprise (Helfman et al., 2009).

Model of corporate training, which puts a focus on in-service training (Bazarova and Eremina, 2002).

Innovative model, which orients corporate training process towards an innovative way, relying on the bank of standard solutions for typical problems (Kartashova, 2009).

Personality-oriented model focuses on various aspects that help the employee to develop his creative approach towards his professional duties performance (Kibanov and Durakova, 2005).

Information and advisory model suggests innovative character by integrating two interrelated processes: Training (informing), the result of which is an increase of knowledge and competence of employees and consultancy, the result of which is personal problems solving of professional staff (Zevunov, 2009).

Metacognitive model is aimed to form a "learning organization" that can act as a subject of corporate training and to hold an open and reflective cognitive position towards external and internal organizational environment (Karpov and Skityaeva, 2008).

Multiplication model is in great request among enterprises with limited financial resources and which are forced to have their teachers-multiplicators (Morita, 1990).

Model of corporate competition is aimed at creating a competitive advantage among company's staff in order to provide competition within the organization (Isaev et al., 2013).

Leadership model is aimed at purpose-oriented shaping of leadership qualities among managerial staff and includes an assessment of leadership style of the training process participants, team development, intergroup development, drawing up an organizational model based on leadership principle and its implementation as well (Vandenbusscke et al., 2006). 


\section{RESULTS}

Analysis of the socio-economic and educational literature and in-house training models review, have allowed us to identify a multi-dimensional classification of training types, both in the company and outside of it.

\subsection{According to Local Characteristics}

In-house training, carried out both in the workplace and with a separation from employment on the premises; out-of-house training including training, refresher courses in specialized vocational-technical schools and training centers. This type of training is more effective, but is associated with the additional financial costs and distraction of an employee's from his official duties. In this case, deliberately the environment is changed, the worker leaves his daily affairs, the training is carried out in the course of lectures, workshops training (business games, manufacture situation).

\subsection{According to Scale Characteristics}

Centralized training is carried out and funded at the level of the corporation, which determine whom to train appropriately among the staff members within the company, but with the separation from work, whom to second to the passage of a university course and how to link the increase of new competencies of employees with their career development; decentralized training - at the level of individual production units a choice of educational programs and their funding and organization, training is carried out usually on the job;

\subsection{According to Temporal Characteristics}

Long-term training, suggesting the kind of employees' education, which is strategic for the company and looks like investing in long-term projects (the second higher education, MBA); short-term training, which implies training of employees in the short term in response to critical enterprises cases emerging (seminars, workshops, conferences) (1 to 5 days);

\subsection{According to the Target Characteristics}

Fragment training that does not require investments and not related to the objectives of the specific organizations, which gives basic in training centers (usually this kind of training is recognized hopeless by experts); formalized training means that such training is considered as a part of the professional career and is combined with the resource requirements of the company and student's personal aspirations. The basis is the basic knowledge and specialized courses on the development of individual skills; targeted training, suggesting ongoing training to address specific business challenges.

The above considered types of technical specialists training in the company are carried out in ways that we have classified by the following forms.

\subsection{On the Level of Employment in the Workplace}

Training in the workplace, ensuring a close link directly to the process of the employee realized through mentoring and supervision using techniques of increasingly complex tasks and addressed to gain experience, manufacturing instructions, job rotation, use of an employee as an assistant, the delegation of authority-the roles and responsibilities (Theory Course in vocational and technical schools and practical training at the enterprise). Training at the job is characterized by its practical orientation, directly connected to the production functions of the employee, providing, as a rule, significant opportunities for repetition and re-fixing of the learned material. In this sense, this type of training is optimal for the skills' development required to meet current production problems. At the same time, such training is often too specific to develop the potential of the employee, to build new behavioral and professional competencies, as it does not allow him to ignore the current situation at the workplace and to go beyond the traditional behavior. To achieve these goals outside of the workplace training programs are more effective.

Training out of work, which implies studying in the organization, carried out by experts from both internal and external organizations, external experts, as well as specialized vocational-technical schools and training centers.

\subsection{On the Level of Characteristics Kinds}

- Traditional training based on information and rationalization, oriented on knowledge that will be useful in the future and adapt the company's employees to its needs, carried out by teachers, organized in the form of local workshops. Traditional training programs are stable and are prepared by course teachers

- Integrated education, based on the information, rationalization, communication and emotions, focused on a specific change of the company and its employees at the same time, carried out through the group and inter-group communications including all subjects of study, involving the free choice of forms 
depending on the need and situation. Integrated training programs are flexible, adapted to the situation and suggest the participation of enterprise executives in their development

\subsection{On the Level of Relevance of the Study}

- Supporting study involves the assimilation of fixed views, methods and rules in order to work effectively in a well-known and recurring situations, to develop students' ability to solve the problems that are relevant. The investigators note that in many modern organizations supporting training is sufficiently developed and used. Since this type of training is aimed primarily at maintaining the current situation in the organization, the training and education of employees are corresponded rather to "work in the past" than the "work in the future" and little are focused on what may happen to the organization and activities of workers tomorrow. Programs of this type of training is particularly effective for the new knowledge transfer to replace outdated one and gaps in knowledge and skills of employees and are designed to maintain the existing system

- Advanced training is focused on the future, organizations' training to work in the new environment. The development of innovative training programs must be preceded by the forecast of the organization's needs to change professional human resources according to the corresponding changes in the external environment, technology and operations management system. The advanced training usually has to deal with the problems that may be so unique that there will be no opportunities to learn through trial and error, problems, solution of which is not yet known and the formulation of which can cause controversy and doubt. Therefore, this type of training is often neglected and many organizations had serious difficulties with their own adaptation to environmental changes. Administrative and management staff are usually well prepared to supported study, but the duty of a manager, who is oriented on organizations' development-is to provide the potential for this development, which is possible only through advanced training (Zamanbekov, 2013)

\subsection{On the Number of Participants Involved}

- Individual training in which trainee specialist is attached to the most qualified instructor-the instructor of industrial training, not liberated from work. Job training is carried out directly at the workplace on the basis of the training program and recorded in the Journal of industrial training

- Brigade training, suggesting a group training of young professionals in groups of 5-10 people

- Course training, carried out in the educational unit of the enterprise, in the training center or centers of other organizations. Course form is the form of learning complex professions mastery of which is connected with the study of a significant amount of special and general technical and economic knowledge.

\section{DISCUSSION}

Previous researches were devoted to the peculiarities of corporate education (Karpov and Skityaeva, 2008; Kartashova, 2009; Tyunikov and Maznichenko, 2005), to their content and structure revealing (Bazarova and Eremina, 2002; Minzov, 2014). Corporate education types and forms are also presented in scientific works (Morita, 1990; Minzov, 2014; Zevunov, 2009). However, it should be admitted that there is a lack of researches on the development and theoretical justification of corporate training types and forms classification.

\section{CONCLUSION}

Hence, a model of corporate education was presented (corporate competition, problem-oriented, complementary, displacing, innovative, personalityoriented, information and advisory, metacognitive, multiplicational and leadership models) allows that they are independent and self-sufficient, contributing to solving urgent problems of employees corporate education in present-day companies and organizations. Among presented models, the multi-dimensional classification of corporate education types in modern enterprises has been theoretically justified and augmented: by local parameters (internal and external corporate training), by scale parameters (centralized and decentralized training), by temporal parameters (longterm and short-term training), by purpose parameters (fragmentary, formalized and intentional training). These presented corporate training types are implemented as on-the-job training and out-of-job training; traditional and integrated training; supportive and anticipatory training; individual and team training, course training.

The classification of types and forms of corporate training can be useful for teaching and methodical centers of the enterprises in their personnel in-house training organization and planning, for training 
centers and workers, specialists and enterprises and organizations managers training, as well as for researchers, who is involved in structural and systemic analysis of corporate education problems. On the effectiveness of companies corporate training does not affect chaotic using of the presented forms and types as of in-company, so of out-of company training, but their system integrity and consequent combination.

\section{RECOMENDATION}

This article does not claim to be all the problems solving in the search for effective kinds and forms of corporate education, as its results are rather theoretical. For further research the following directions are perspective: The problem of development in organizational, substantive and technical aspects of each kind and form of corporate education; the mechanisms and technologies of effective corporate training as of inexperienced personnel, so of specialists; organizational-pedagogical conditions, contributing to the realization of one or another form of corporate training; methodological recommendations, contributing to the optimal implementation of corporate training, taking into account the requirements of a specific manufacture, depending on its possibilities of one or another form of corporate training application.

\section{REFERENCES}

Bazarova, T.Y. and B.L. Eremina, 2002. Personnel Management: A Textbook for High Schools. 1st Edn., UNITY Press, pp: 560.

Helfman, E.G., M.I. Holodnaya, I.A.Bashirova and T.L. Blinov, 2009. Modern Problems of Education: Theory and Practice. 1st Edn., Ural State Pedagogical University Press, pp: 298.

Isaev, A.V., L.A. Isaeva and A.G. Kravets, 2013. Individualized educational trajectory: Educational courses integration submitted. World Appl. Sci. J., 24: 62-67. DOI: 10.5829/idosi.wasj.2013.24.itmies.80013

Karpov, A.V. and I.M. Skityaeva, 2008. In-house training as a resource for organizational development. Professional Educ. J.

Kartashova, L.V., 2009. Human Resource Management Textbook Textbooks for Program MBA. 1st Edn., INFRA-M Press, pp: 107.
Kibanov, A.Y. and I.B. Durakova, 2005. Management Staff of the Organization. 1st Edn., Exam Press, pp: 414.

Klucharev, G.A., 2010. Professional education: characteristics, efficiency, with prospects. Sociol. Stud., 2: 83-92.

Manheim, J., 1994. Strategic Public Diplomacy and American Foreign Policy: The Evolution of Influence. 1st Edn., Oxford University Press, USA, ISBN-10: 0195087380, pp: 209.

Masalimova, A.R., 2013. Corporate Training the Mentors. 1st Edn., Printing Service-XXI Century Press, pp: 183.

Minzov, A.S., 2014. Corporate education in Russia: The essence and aims.

Morita, A., 1990. Made in Japan. 1st Progress Press, pp: 206.

Nelson, R. and Phelps E., 1966. Investment in humans, technological diffusion and economic growth. Am. Econom. Rev., 56: 69-75.

Ozhegov, S.I. and N.Y. Shvedova, 2007. Dictionary of Russian Language-80000 Words and Phraseological Expressions. 1st Edn., IT Technology Institute Press, pp: 943.

Seddigi, Z.S., L.F. Capretz and D. House, 2009. A multicultural comparison of engineering students: Implications to teaching and learning. J. Soc. Sci., 5: 117-122. DOI: 10.3844/jssp.2009.117.122

Tyunnikov, Y.S. and M.A. Maznichenko, 2004. Scenario approach in teacher interaction. School Technol., 2: 34-42.

Tyunikov, Y. and M. Maznichenko, 2005. Corporate culture as a factor in the competitiveness of the university. Higher Educ. Russia J., 10: 69-77.

Vandenbusscke, J., A. Aghion and C. Meghir, 2006. Growth distance to frontier and composition of human capital. J. Econo. Growth, 11: 97-127. DOI: 10.1007/s10887-006-9002-y

Zamanbekov, S.Z., 2013. Innovative development of engineering is a basis of economy modernization of Kazakhstan. Middle-East J. Scientific Res., 16: 1183-1186. DOI: 10.5829/idosi.mejsr.2013.16.09.11979

Zevunov, A.V., 2009. Corporate training small businesses, M.S. Thesis, Nizhny Novgorod State University by N.I.Lobachevsky name, Russia, MI. 